\title{
Convenient Synthesis of Micron-sized Macro Porous Polymers with Silica on their Surfaces and Excellent Adsorption Performance for Pb(II) Ion
}

Kannan RS ${ }^{1 *}$, Kavitha $\mathrm{K}^{2}$, Muthukrishnan $\mathrm{P}^{3}$, Krishnan $\mathrm{NP}^{4}$ and Ilayaraja $\mathbf{M}^{5}$

${ }^{1} P G$ Research and Department of Chemistry, Thiagarajar college, Madurai-625009, Tamil Nadu, India

${ }^{2}$ Department of Chemistry, S. V.N College, Madurai-625009, Tamil Nadu, India

${ }^{3}$ Department of Chemistry, Faculty of Engineering, Karpagam University, Coimbatore-641021 Tamil Nadu, India

${ }^{4}$ Department of Chemistry, K.L.N College of Engineering, Pottapalayam-630611, Tamil Nadu, India

${ }^{5}$ Department of Chemistry, SBM College of Engineering and Technology, Dindigul-624 005, Tamil Nadu, India

\begin{abstract}
The phenol-formaldehyde/silicon dioxide resin (PFSR) adsorbent showed superior adsorption properties for $\mathrm{Pb}$ (II) ion. The aimed composite material was characterized by XRD, FT-IR, SEM and BET techniques. Sorption properties of the synthesized composite powder were evaluated through sorption of lead ions from their aqueous solutions. Batch sorption tests were carried out at different initial heavy metal ion concentrations revealing that the synthesized composite has great selectivity to lead ions. The experimentally obtained sorption results were analyzed using pseudofirst and second order kinetic models to stand on the possible sorption mechanisms indicating the sorption behavior of the studied ions onto PFSR composite belonged to the pseudo-second order kinetic model and the sorption process was a chemical process. Isotherm plots were constructed and analyzed using Langmuir, Freundlich, Temkin, D-R and Jovanoic isotherm models. The $\mathrm{D}-\mathrm{R}$ and Temkin isotherm model provided the best fit for the $\mathrm{Pb}(\mathrm{II})$ ion, revealing the maximum adsorption capacity of $13.74 \mathrm{mg} / \mathrm{g}$. Thermodynamic studies revealed that $\mathrm{Pb}(\mathrm{II})$ adsorption on the PFSR adsorbent is a favorable, spontaneous, and endothermic process.
\end{abstract}

Keywords: Adsorption; Lead; Silicon dioxide; Thermodynamics

\section{Introduction}

Water contamination due to toxic heavy metals has attracted significant attention because of their detrimental effects on the environment and human health. Heavy metal ions such as lead $\left(\mathrm{Pb}^{2+}\right)$, cadmium $\left(\mathrm{Cd}^{2+}\right)$, and nickel $\left(\mathrm{Ni}^{2+}\right)$ are toxic and carcinogenic at even relatively low concentrations. Heavy metals are non-biodegradable and they can accumulate in living organisms. They are generally discharged to the environment from various industrial activities such as smelting, electroplating, painting, mining, leather tanning, alloy and battery manufacturing, etc., posing a significant threat to the environment and public health [1]. Therefore, reliable methods are necessary for the removal of heavy metals from aquatic environment.

A great deal of effort has been devoted to the effective removal of heavy metal ions from environmental matrices. Various treatments techniques available for the removal of toxic metals are adsorption, chemical precipitation, ion exchange, coagulation, reverse osmosis, electrolysis and membrane process, etc. [2-5]. Nowadays, a number of promising processes are used for elimination of heavy metal ions and dyes from wastewaters. Adsorption is a convenient separation process, in which the adsorbent may be of organic, mineral or natural source [6].

Various materials such as zeolites, activated carbon, clays, agricultural wastes, biomass and synthetic polymers were used as an adsorbent $[7,8]$. However, these sorbents suffer from several problems such as low mechanical and thermal stability, high cost and poor sorption capacity. It is well known that biopolymers which are abundant, biodegradable and renewable resources have a high capacity to bind with a variety of waste molecules or ions through chemical and physical interactions. Among them, polysaccharide type biopolymers such as cellulose, chitosan, cyclodextrin, silicon dioxide $\left(\mathrm{SiO}_{2}\right)$ have received more attention [9].

In this work, with an effort to improve the metal complexing ability and selectivity of Silicon dioxide polymer was synthesized and used to graft on the phenol-formaldehyde surface. The aim of this work was to study the utility of PFSR, low cost as well as non-hazardous material, as an adsorbent for $\mathrm{Pb}(\mathrm{II})$ removal from aqueous solution by batch experiments. The effect of experimental parameters such as initial concentration, contact time and temperature was investigated. Furthermore, equilibrium, kinetic and thermodynamic studies on the adsorption of $\mathrm{Pb}(\mathrm{II})$ onto the PFSR were also carried out for the design of adsorption process.

\section{Materials and Methods}

\section{Materials}

The chemicals used in the present study were Con. Sulfuric acid (Specific gravity=1.82), Formaldehyde $(37-40 \%$ solution) and Phenol (Density $=1.057 / \mathrm{gm}$ ). Silicon dioxide (molecular weight, 79.87 ) was supplied by SRL chemicals, Mumbai, India. The Lead nitrate $\left(\mathrm{Pb}\left(\mathrm{NO}_{3}\right)_{2}\right.$ M.W. 331.21) was obtained from RANKEM chemicals New Delhi, India. All the chemicals used were analytical grade. The double distilled (DD) water was used throughout the investigation.

\section{Preparation of PFCR composites}

Phenol and Con. Sulfuric acid (1:1) and $0.5 \mathrm{mg}$ of silicon dioxide were mixed slowly with constant stirring in an ice bath. The mixture was then, heated to $70^{\circ} \mathrm{C}$ for three hours, cooled and kept overnight.

*Corresponding author: Kannan RS, Assistant Professor, PG Research and Department of Chemistry, Thiagarajar college, Madurai-625009, Tamil Nadu, India Tel: +91-9486162075; Fax: +91-4522312375; E-mail: rsamkannan@yahoo.co.in

Received April 01, 2015; Accepted April 25, 2015; Published April 29, 2015

Citation: Kannan RS, Kavitha K, Muthukrishnan P, Krishnan NP, Ilayaraja M (2015) Convenient Synthesis of Micron-sized Macro Porous Polymers with Silica on their Surfaces and Excellent Adsorption Performance for $\mathrm{Pb}$ (II) lon. J Environ Anal Toxicol 5: 291. doi:10.4172/2161-0525.1000291

Copyright: (c) 2015 Kannan RS, et al. This is an open-access article distributed under the terms of the Creative Commons Attribution License, which permits unrestricted use, distribution, and reproduction in any medium, provided the original author and source are credited. 
The product was polymerized with formaldehyde solution $(12 \mathrm{ml})$ in an ice bath, and then heated to $70^{\circ} \mathrm{C}$ for three hours and the product was cured, then ground washed with DD water, to remove the free acid. Then the sample was dried at $70^{\circ} \mathrm{C}$ for $16 \mathrm{~h}$. Then the composite resin were sieved and preserved for characterization and further studies.

\section{Adsorption experiments}

Batch mode adsorption studies were carried out by adding certain amount of adsorbent and $40 \mathrm{ml}$ of metal ion solutions of certain concentrations, dose, contact time and temperatures in a thermo stated water bath shaker with a shaking of $200 \mathrm{rpm}$. The samples were withdrawn from the shaker at predetermined time intervals and solutions were separated from the adsorbent by centrifugations at 4000 $\mathrm{rpm}$ for $5 \mathrm{~min}$. To determine the residual metal ion concentration, the absorbance of the supernatant solution was measured before and after treatment using atomic absorption (Elico SL-173) spectrometry at wavelength of $283.3253 .7 \mathrm{~nm}$ for $\mathrm{Pb}$ (II). Experiments were carried out twice and the concentrations given were average values. The initial metal ion concentrations in the test solution and the contact time were varied to investigate their effect on the adsorption kinetics. The $\mathrm{pH}$ of the metal ion solution was adjusted by using $\mathrm{NaOH}$ or $\mathrm{HCl}$ solution and a $\mathrm{pH}$ meter. The adsorption studies were carried out at different temperatures ( $308 \mathrm{~K}, 318 \mathrm{~K}$ and $328 \mathrm{~K})$. This was used to determine the effect of temperature on the thermodynamic parameters.

The amount of adsorption in batch experiments and adsorption efficiency were calculated as follows:

$$
\begin{aligned}
& \mathbf{q}=\left(\mathbf{C}_{\mathbf{o}}-\mathbf{C}_{\mathbf{e}}\right) \mathbf{V} / \mathbf{m} \\
& \text { Efficiency }(\%)=\left(\mathbf{C}_{\mathbf{o}}-\mathbf{C}_{\mathbf{e}}\right) / \mathbf{C}_{\mathbf{o}} \times \mathbf{1 0 0} \\
& \text { Where } \mathrm{C}_{\mathrm{o}} \quad \text { is the initial concentration }(\mathrm{mg} / \mathrm{l}) \\
& \mathrm{C}_{\mathrm{e}} \quad \text { is the equilibrium concentration }(\mathrm{mg} / \mathrm{l}) \\
& \mathrm{V}
\end{aligned}
$$

\section{Surface characteristic of the adsorbent}

Surface area and porous size distribution of PFCR sample were measured by nitrogen adsorption analysis (Quantachrome V5.02). Crystal structure of sample was determined by performing X-ray diffraction (XRD) on SHIMADZU $6000 \mathrm{X}$-ray diffraction spectrometer. Surface morphologies were examined by a scanning electron microscope (SEM, JEOL (JSM 6390) with the working distance of 9.9 $\mathrm{mm}$ and an accelerating voltage of $30 \mathrm{keV}$. The SEM was equipped with an energy dispersion spectrometer (EDS) and it was used to perform the analysis of chemical constituents of the adsorbent. Infrared absorption spectroscopy (IR) spectra were measured at room temperature on a Fourier transform infrared (FTIR) spectroscopy (8400s SHIMADZU spectrometer) using the $\mathrm{KBr}$ pellet technique.

\section{Results and Discussion}

\section{Characterization of the adsorbent}

BET: The specific surface area was determined using the BET equation applied to the adsorption data. The surface area of PFSR was found to be $28.16 \mathrm{~m}^{2} / \mathrm{g}$. Total pore volume is $11.2 \mathrm{~cm}^{3} / \mathrm{g}$ and pore size is $348.7 \AA$. PFSR has a relatively promising surface area. In particular, the micro porosity of solids can be assessed, within the limits of the BET model, provided that the reference isotherm is correctly chosen.
All these results are proved to be valid whatever the nature of the adsorbent-adsorbate pair used. Some isotherms obtained with $\mathrm{N}_{2}, \mathrm{Ar}$, $\mathrm{CO}, \mathrm{O}_{2}, \mathrm{CO}_{2}$ are reported (Figure 1).

FTIR: FTIR spectra of the PFSR, PFSR-Pb(II) were shown in Figure 2. The main bands observed in the IR spectra of PFSR, (Figure 2a). FTIR data of PFSR, showed that characteristic band at 3392.7, 1631.7, 1463.0, $1020 / \mathrm{cm}$ and 869 correspond to the free $\mathrm{OH}, \mathrm{C}=\mathrm{C}, \mathrm{C}-\mathrm{H}$ stretching, $\mathrm{C}-\mathrm{O}-\mathrm{C}$ and $\mathrm{C}=\mathrm{CH}_{2}$ stretching vibrations respectively.

FTIR data of PFSR-Pb (II) showed that characteristic band at $3190.1,1593.0,1459.7$ and $1023.0 / \mathrm{cm}$ correspond to the $\mathrm{OH}, \mathrm{C}=\mathrm{O}$, $\mathrm{C}-\mathrm{CH}_{2}$ and $\mathrm{C}-\mathrm{O}-\mathrm{C}$ stretching vibrations respectively (Figure $2 \mathrm{~b}$ ), indicated that mostly the bonded $\mathrm{OH}$ groups, $\mathrm{C}=\mathrm{O}$ stretching, $\mathrm{C}-\mathrm{CH}_{2}$

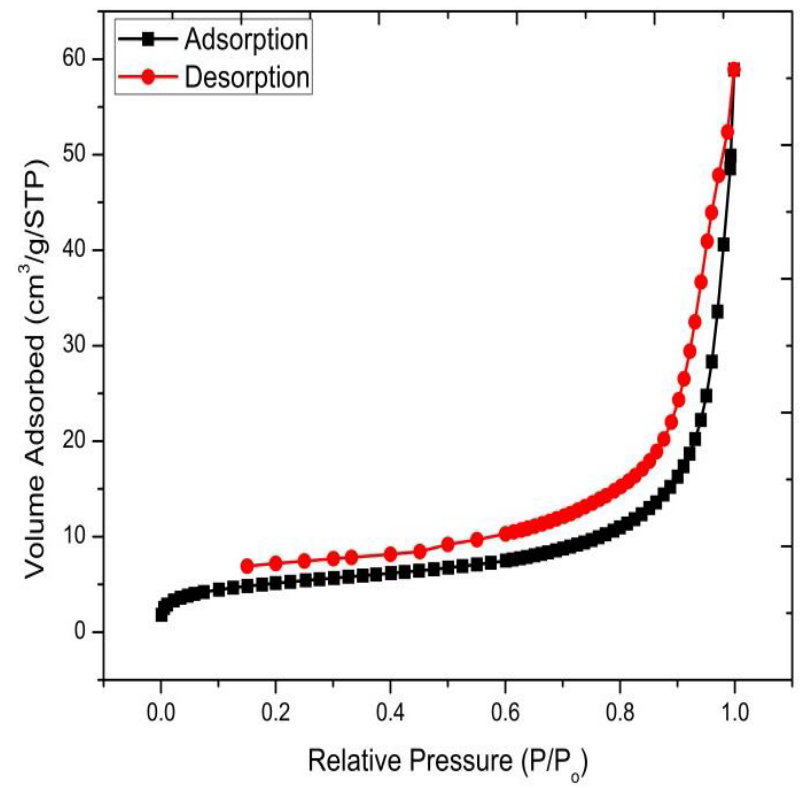

Figure 1: Adsorption-desorption isotherms of nitrogen at $77 \mathrm{~K}$ on PFSR.

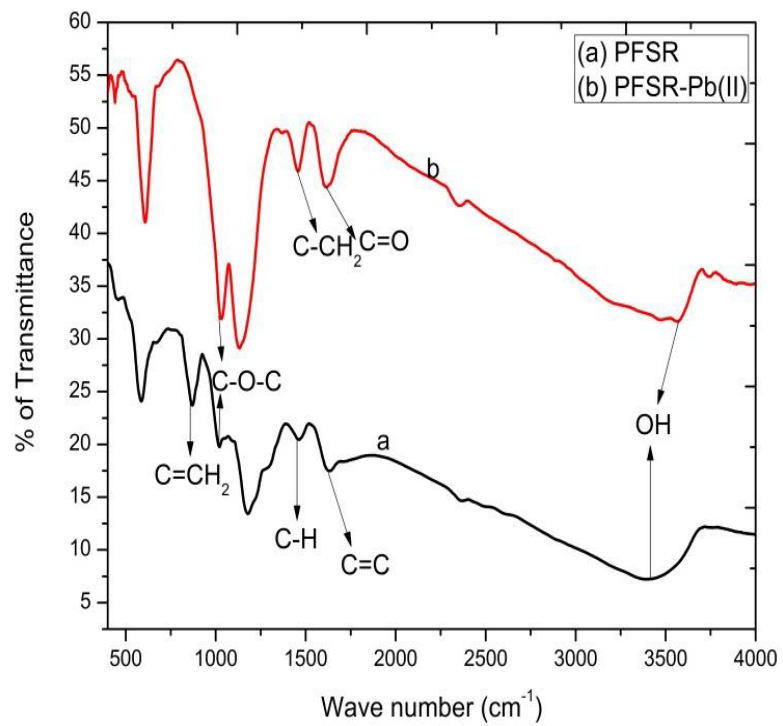

Figure 2: FTIR spectra of (a) PFSR (b) PFSR-Pb(II). 
Citation: Kannan RS, Kavitha K, Muthukrishnan P, Krishnan NP, llayaraja M (2015) Convenient Synthesis of Micron-sized Macro Porous Polymers with Silica on their Surfaces and Excellent Adsorption Performance for Pb(II) Ion. J Environ Anal Toxicol 5: 291. doi:10.4172/2161-0525.1000291

bending vibrations and $\mathrm{C}-\mathrm{O}-\mathrm{C}$ vibrations were involved in $\mathrm{Pb}(\mathrm{II})$ ion adsorption. There were clear band shifts and intensity increases in Figure $2 \mathrm{~b}$. These findings suggest that there is attachment of $\mathrm{Pb}(\mathrm{II})$ on the PFSR.

XRD: The XRD patterns as shown in Figure 3 were performed to analyze the crystalline nature. The diffraction spectrum of PFSR did not show any obvious crystalline peak at the scan range $10-90^{\circ}$ there by indicating the amorphous phase of PFSR.

SEM: SEM has been a primary tool for characterizing the surface morphology and fundamental physical properties of the adsorbent surfaces. It is useful for determining the particle shape, porosity and appropriate size distribution of the adsorbent.

However, the particles of PFSR (Figure 4a) had a rough surface with heterogeneous holes and pores that make a large surface area, which indicated that metals can be adsorbed onto its surface. Figure $4 \mathrm{~b}$ showed micrographs of the PFSR surface after adsorbed $\mathrm{Pb}$ (II) ions, the surface of PFSR was relatively smoother and less porous because of the formation of a layer over the adsorbent surface after adsorption of metal ions.

EDX: Further confirmation of the adsorption of $\mathrm{Pb}(\mathrm{II})$ on PFSR was done by energy dispersive X-ray analysis (EDX) (Figure 5a) for the unloaded PFSR, did not show any characteristic signal for metal ions, but only showed for the three major constituents, i.e., $\mathrm{C}, \mathrm{O}$ and $\mathrm{Si}$. Whereas for $\mathrm{Pb}(\mathrm{II})$ loaded PFSR (Figure $5 \mathrm{~b}$ ) signals of presence of $\mathrm{Pb}$ (II) were observed. This showed the diffusion or accumulation of metal ions onto the surface of PFSR.

\section{Effect of initial concentrations}

Effect of initial $\mathrm{Pb}$ (II) ion concentration was studied at different initial metal ion concentrations in the range of $10-50 \mathrm{mg} / \mathrm{l}$ at $298 \mathrm{~K}$ with $0.200 \mathrm{~g}$ PFSR at $120 \mathrm{~min}$. The percentage of $\mathrm{Pb}(\mathrm{II})$ ions adsorption at different metal concentrations using PFSR, decreased with increase in metal ion concentration. This may be due to saturation of available adsorption sites onto PFSR. The effect of initial concentration on the removal of $\mathrm{Pb}(\mathrm{II})$ by the adsorbent was indicated in Table 1 .

\section{Effect of contact time}

The effect of contact time on the adsorption of $\mathrm{Pb}(\mathrm{II})$ at $10 \mathrm{mg} / \mathrm{l}$ metal ion concentration. The $\mathrm{Pb}(\mathrm{II})$ adsorption increased with increasing the contact time, the maximum removal of $\mathrm{Pb}$ (II) ions occurred at $120 \mathrm{~min}$, after which there were no major significant changes. The equilibrium was reached at $120 \mathrm{~min}$ for the metal ions. Following this, the adsorption rate was uniform as there was no significant change in adsorption with the increasing time. The initial fast adsorption is due to the availability of more active sites and more functional groups which participate in the lead uptake till equilibrium is attained and thereafter, there was no further adsorption. All the results were presented in Table 2 .

\section{Effect of adsorbent mass}

The effect of adsorbent dosage on lead and mercury removal was

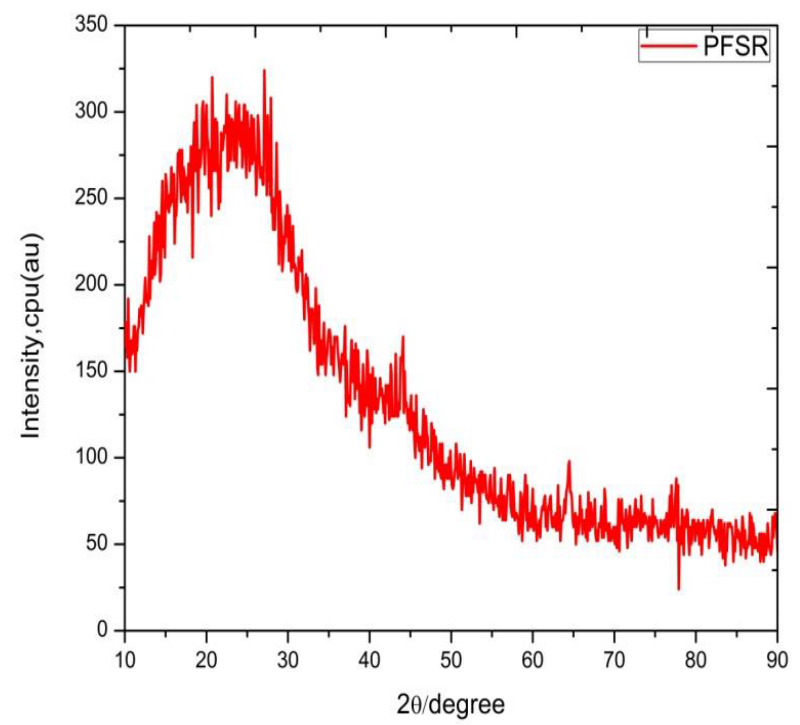

Figure 3: XRD pattern of PFSR.
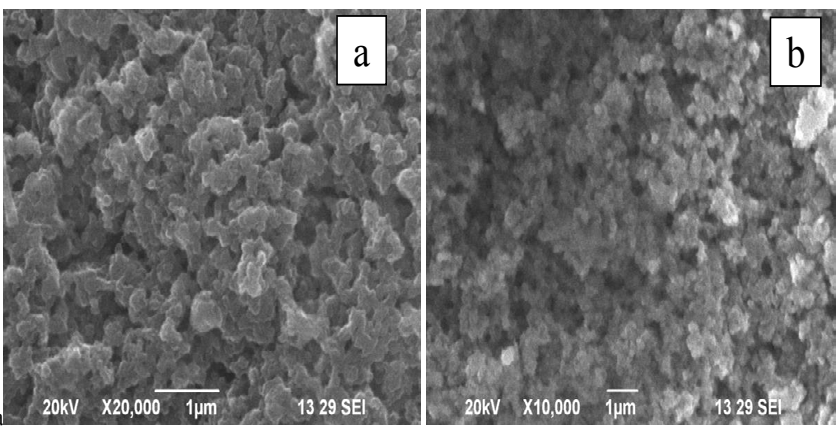

Figure 4: The SEM images of (a) PFSR (b) PFSR-Pb(II).

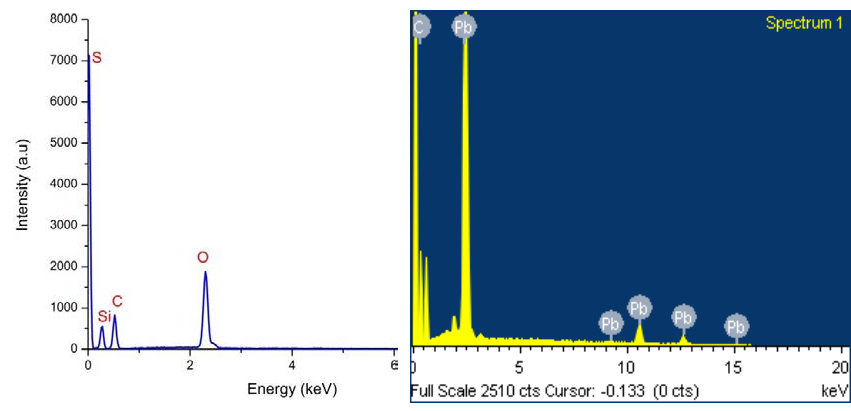

Figure 5: Energy dispersive spectra of (a) PFSR (b) PFSR-Pb (II).

\begin{tabular}{|l|c|c|c|c|c|c|c|c|c|c|}
\hline \multirow{2}{*}{ Concentrations } & \multicolumn{4}{|c|}{ Adsorption efficiency (\%) } & \multicolumn{4}{|c|}{ Amount of adsorbed, q (mg/g) } \\
\cline { 2 - 9 } & 10 & 20 & 30 & 40 & 50 & 10 & 20 & 30 & 40 & 50 \\
$\mathrm{~Pb}$ (II) & 96.7 & 48.2 & 27.3 & 27.8 & 19.2 & 80.8 & 51.4 & 26.6 & 29.0 & 19.4 \\
\hline
\end{tabular}

Table 1: Effect of initial concentrations of $\mathrm{Pb}$ (II).

\begin{tabular}{|c|c|c|c|c|c|c|c|c|c|c|}
\hline \multirow[b]{2}{*}{ Contact time } & \multicolumn{5}{|c|}{ Adsorption efficiency (\%) } & \multicolumn{5}{|c|}{ Amount of adsorbed, $q(\mathrm{mg} / \mathrm{g})$} \\
\hline & 30 & 60 & 120 & 180 & 240 & 30 & 60 & 120 & 180 & 240 \\
\hline $\mathrm{Pb}$ (II) & 98.6 & 98.8 & 99.1 & 99.1 & 99.1 & 57.2 & 57.4 & 57.6 & 57.6 & 57.6 \\
\hline
\end{tabular}

Table 2: Effect of contact time. 
studied by varying the amount PFSR between $0.050-0.250 \mathrm{~g}$. It is evident from Table 3, that the removal of $\mathrm{Pb}(\mathrm{II})$ was increased with increase in PFSR dose until a constant value was achieved. That is, the percentage removal increased from $37.08 \%$ to $99.1 \%$ for $\mathrm{Pb}(\mathrm{II})$ as the PFSR adsorbent. This can be associated with higher available surface area and more available sorption sites at higher sorbent doses. The optimum adsorbent dosage was found to be $0.200 \mathrm{~g}$ for $\mathrm{Pb}(\mathrm{II})$ metal ions.

\section{Adsorption isotherms}

The adsorption isotherm shows how the adsorbate molecules are distributed between the liquid phase and solid phase. The analysis of the isotherm data by fitting them to different isotherm model is an important step to find the suitable model that can be used for design purposes.

In current study, a comparison of Langmuir, Freundlich, Temkin, $\mathrm{D}-\mathrm{R}$ and Jovanoic isotherm models were fitted to analyze the equilibrium data. The linear form of Langmuir isotherm was represented by the following equation

$$
\frac{\mathbf{C}_{e}}{\mathbf{q}_{e}}=\frac{1}{K_{L} \times \mathbf{q}_{m}}+\frac{\mathbf{C}_{e}}{\mathbf{q}_{m}}
$$

Where $\mathrm{q}_{\mathrm{m}}$ is monolayer (maximum) adsorption capacity $(\mathrm{mg} / \mathrm{g}$ ) and $K_{L}$ is Langmuir constant related to energy of adsorption $(1 / \mathrm{mg})$ obtained from the slope and intercept values of the plot $\mathrm{C}_{\mathrm{e}} / \mathrm{q}_{\mathrm{e}}$ against $\mathrm{C}_{\mathrm{e}}$ respectively.

According to [10], the essential characteristics of Langmuir isotherm can be explained in terms of dimensionless constant separation factor $\left(\mathrm{R}_{\mathrm{L}}\right)$, which is defined by following equation:

$$
\mathbf{R}_{\mathrm{L}}=\mathbf{1} / \mathbf{1}+\mathbf{K}_{\mathrm{L}} \mathbf{C}_{\mathbf{0}}
$$

Where, $\mathrm{K}_{\mathrm{L}}(\mathrm{L} / \mathrm{mg})$ is the Langmuir constant related to the energy of adsorption and $\mathrm{C}_{\mathrm{o}}(\mathrm{mg} / \mathrm{l})$ is the initial concentration of metal ions. The $R_{L}$ value indicates the type of the isotherm to be either unfavorable $\left(\mathrm{R}_{\mathrm{L}}>1\right)$, linear $\left(\mathrm{R}_{\mathrm{L}}=1\right)$, favorable $\left(0<\mathrm{R}_{\mathrm{L}}<1\right)$, irreversible $\left(\mathrm{R}_{\mathrm{L}}=0\right)$.

The linear form of Freundlich isotherm equation was employed for the adsorption of $\mathrm{Pb}$ (II) onto the PFSR adsorbents was represented by

$$
\log \mathbf{q}_{\mathrm{e}}=\log \mathrm{K}_{\mathrm{F}}+\mathbf{1} / \mathbf{n} \log \mathrm{C}_{\mathrm{e}}
$$

Where $\mathrm{q}_{e}$ is amount of $\mathrm{Pb}(\mathrm{II})$ adsorbed at equilibrium $(\mathrm{mg} / \mathrm{g}), \mathrm{C}_{\mathrm{e}}$ is the equilibrium concentration of metal ion in solution $(\mathrm{mg} / \mathrm{l})$, A plot of $\log \mathrm{q}_{\mathrm{e}}$ against $\log \mathrm{C}_{\mathrm{e}}$ gives a straight line, $\mathrm{K}_{\mathrm{F}}$ and $\mathrm{n}$ are constant incorporating factors affecting the adsorption capacity and intensity of adsorption calculated from the intercept and slope of the plot respectively.

The Dubinin-Radushkevich [11] isotherm has been used to describe the sorption of metal ions; the equation has the form:

$$
\text { In } q_{e}=\operatorname{In} q_{m}-\beta \varepsilon^{2}
$$

where $q_{e}$ is the amount of $\mathrm{Pb}(\mathrm{II})$ adsorbed per unit weight of adsorbent $(\mathrm{mg} / \mathrm{g}), \mathrm{q}_{\mathrm{m}}$ is the maximum sorption capacity, $\beta$ is the activity coefficient related to mean sorption energy, and $\varepsilon$ is the Polanyi potential, which is equal to:

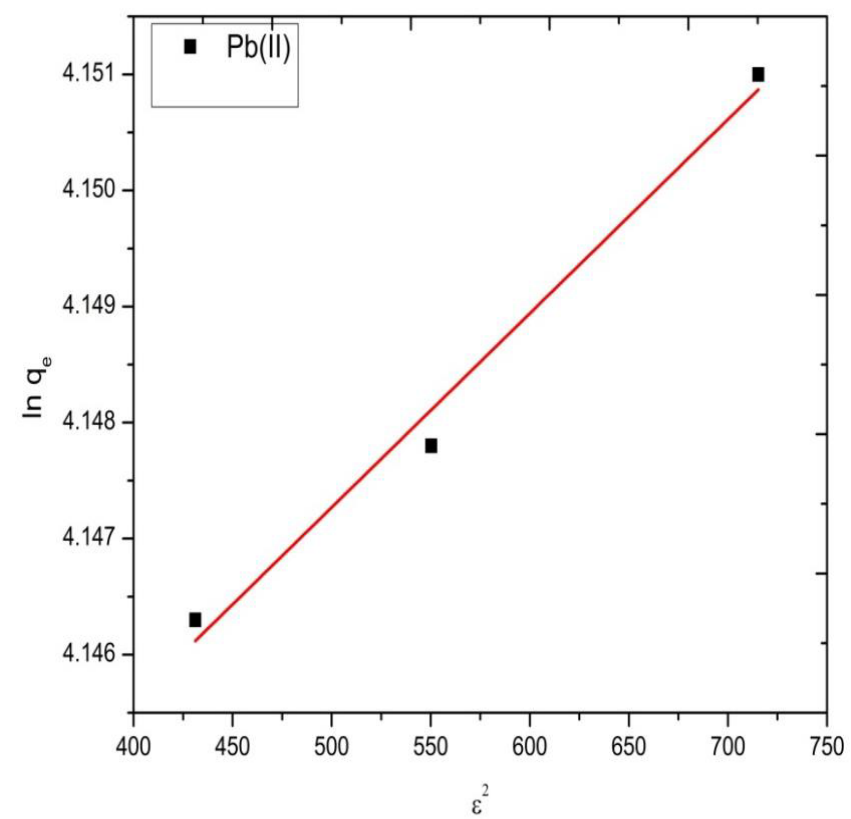

Figure 6: $\mathrm{D}-\mathrm{R}$ isotherm plots for the adsorption of $\mathrm{Pb}$ (II) onto PFSR.

\section{$\varepsilon=\operatorname{RT} I N\left(1+1 / C_{\mathrm{e}}\right)$}

where $\mathrm{R}$ is the gas constant $(\mathrm{kJ} / \mathrm{mol} \mathrm{K})$ and $\mathrm{T}$ is the temperature (K).The saturation limit $\mathrm{q}_{\mathrm{m}}$ may represent the total specific microspore volume of the sorbent. The sorption potential is independent of the temperature but varies according to the nature of sorbent and sorbate.

From Figure 6 a plot of $\ln \mathrm{q}_{\mathrm{e}}$ versus $\varepsilon^{2}$ gave straight line from which the values of $\beta$ and $\mathrm{q}_{\mathrm{m}}$ for the PFSR adsorbents were calculated. Using the value of $\beta$, the mean free energy, $\mathrm{E}(\mathrm{kJ} / \mathrm{mol})$ employing Eq.8 [12]

$$
\mathrm{E}=1 /(2 \beta)^{1 / 2}
$$

The magnitude of $\mathrm{E}$ may characterize the type of the adsorption as chemical ion exchange $(\mathrm{E}=8-16 \mathrm{~kJ} / \mathrm{mol})$, or physical adsorption $(\mathrm{E}<8$ $\mathrm{kJ} / \mathrm{mol}$ ). The mean free energy of adsorption for the present study was found to be $31.6 \mathrm{~kJ} / \mathrm{mol}$ for $\mathrm{Pb}(\mathrm{II})$. This implies that, the adsorption of $\mathrm{Pb}$ (II) on PFSR may be considered as chemical adsorption process.

The Temkin isotherm [13] is given as

$$
\mathbf{q}_{\mathrm{e}}=\mathrm{B}_{1} \ln \mathbf{K}_{\mathrm{T}}+\mathbf{B}_{1} \ln \mathbf{C}_{\mathrm{e}}
$$

Where $\mathrm{K}_{\mathrm{T}}(1 / \mathrm{g})$ is the equilibrium binding constant, corresponding to the maximum binding energy and constant $B_{1}$ is related to heat of adsorption calculated from the intercept and slope of the plot $\mathrm{q}_{e}$ against $\ln \mathrm{C}_{\mathrm{e}}$ respectively (Figure 7).

\begin{tabular}{|c|c|c|c|c|c|c|c|c|c|c|}
\hline \multirow[b]{2}{*}{ Dose $(\mathrm{g})$} & \multicolumn{5}{|c|}{ Adsorption efficiency (\%) } & \multicolumn{5}{|c|}{ Amount of adsorbed, q (mg/g) } \\
\hline & 0.050 & 0.100 & 0.150 & 0.200 & 0.250 & 0.050 & 0.100 & 0.150 & 0.200 & 0.250 \\
\hline $\mathrm{Pb}(\mathrm{II})$ & 37.0 & 63.1 & 94.2 & 98.3 & 99.1 & 10.8 & 92.0 & 91.4 & 71.6 & 57.7 \\
\hline
\end{tabular}

The Jovanoic isotherm [14], which is based on the same assumptions of the Langmuir isotherm, also considers the possibility of some mechanical contacts between the adsorbing and desorbing molecules on the homogeneous surface and can be represented in a linear form as follows: 


$$
\ln \mathbf{q}_{\mathrm{e}}=\ln \mathbf{q}_{\mathrm{m}}+\mathbf{K}_{\mathrm{J}} \mathbf{C}_{\mathrm{e}}
$$

Where, $\mathrm{q}_{\mathrm{m}}$ is the maximum amount adsorbed (in $\mathrm{mg} / \mathrm{g}$ ) and $\mathrm{K}_{\mathrm{J}}$ (in $\mathrm{L} / \mathrm{mg}$ ) is the constant related to the energy of adsorption. The $\mathrm{q}_{\mathrm{m}}$ and $\mathrm{K}_{\mathrm{I}}$ can be calculated from the intercept and slope of the linear plot of $\ln \mathrm{q}_{\mathrm{e}}$ against $\mathrm{C}_{\mathrm{e}}$.

As seen from Table 4, the correlation coefficients showed that the Temkin and Dubinin-Radushkevich model was the best fitted in five isotherm models. Langmuir, Freundlich and Jovanoic models were not very good.

\section{Kinetic studies}

In order to investigate the mechanism and to determine the rate controlling step of adsorption of $\mathrm{Pb}$ (II) on PFSR, kinetic models were

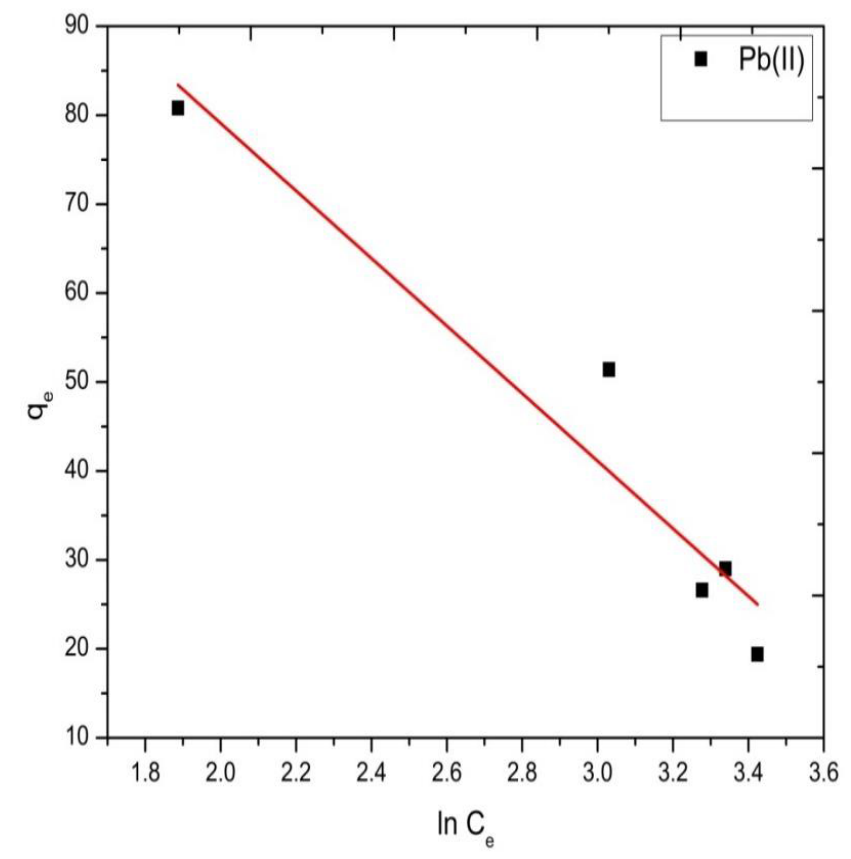

Figure 7: Temkin isotherm plots for the adsorption of $\mathrm{Pb}(\mathrm{II})$ onto PFSR.

\begin{tabular}{|c|c|c|}
\hline Mathematical models & parameters & $\mathrm{Pb}(\mathrm{II})$ \\
\hline Langmuir isotherm & $\begin{array}{c}\mathrm{R}^{2} \\
\mathrm{~K}_{\mathrm{L}} \times 10^{2} \\
\mathrm{q}_{\mathrm{m}}(\mathrm{mg} / \mathrm{g})\end{array}$ & $\begin{array}{l}0.820 \\
12.73 \\
18.51\end{array}$ \\
\hline Freundlich isotherm & $\begin{array}{l}\mathrm{R}^{2} \\
\mathrm{~K}_{\mathrm{F}} \\
\mathrm{n}\end{array}$ & $\begin{array}{c}0.816 \\
104.2 \times 10^{-4} \\
1.225\end{array}$ \\
\hline Temkin isotherm & $\begin{array}{l}\mathrm{R}^{2} \\
\mathrm{~B}_{1} \\
\mathrm{~K}_{\mathrm{T}}\end{array}$ & $\begin{array}{l}0.926 \\
37.97 \\
155.0\end{array}$ \\
\hline D-R isotherm & $\begin{array}{c}R^{2} \\
B \times 10^{4} \\
q_{m}(\mathrm{mg} / \mathrm{g}) \times 10^{-4} \\
E \mathrm{~kJ} / \mathrm{mol}\end{array}$ & $\begin{array}{c}0.987 \\
5 \\
13.74 \\
31.6 \times 10^{-2}\end{array}$ \\
\hline Jovanoic isotherm & $\begin{array}{c}R^{2} \\
K_{J}(\mathrm{~L} / \mathrm{mg}) \\
\mathrm{q}_{\mathrm{m}}(\mathrm{mg} / \mathrm{g})\end{array}$ & $\begin{array}{l}0.912 \\
0.056 \\
4.862\end{array}$ \\
\hline
\end{tabular}

Table 4: Different adsorption isotherm model parameters for the adsorption of $\mathrm{Pb}$ (II) on PFSR.

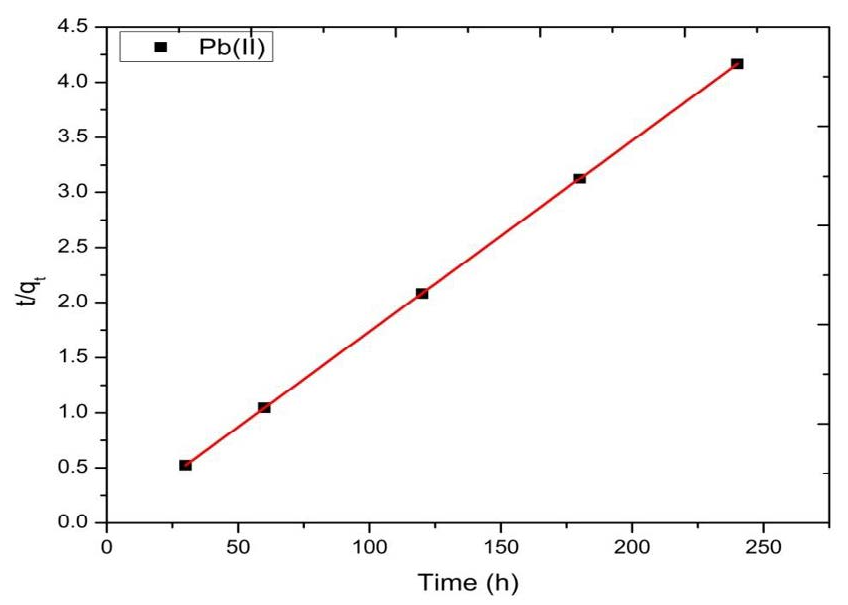

Figure 8: Pseudo-second-order kinetic plots for adsorption of $\mathrm{Pb}$ (II) onto PFSR.

used. The rate constants were calculated by using pseudo-first order and pseudo-second order kinetic models and the rate controlling step was determined by intra-particle diffusion model.

\section{Pseudo-first-order model}

The Lagergren rate equation is one of the most widely used adsorption rate equations for the adsorption of solute from a liquid solution. The pseudo-first-order kinetic model can be expressed by the following equation [15].

$$
\ln \left(\mathbf{q}_{\mathrm{e}}-\mathbf{q}_{\mathbf{t}}\right)=\ln \mathbf{q}_{\mathrm{e}}-\mathbf{k}_{\mathbf{1}} \mathbf{t}
$$

where $\mathrm{q}_{\mathrm{e}}$ and $\mathrm{q}_{\mathrm{t}}$ refer to the amount of metals adsorbed (mg/g) at equilibrium and at any time, $t(\mathrm{~min})$, respectively, and $\mathrm{k}_{1}$ is the equilibrium rate constant of pseudo-first-order sorption $(1 / \mathrm{min})$.

The slope and intercept of the plot of $\log \left(\mathrm{q}_{\mathrm{e}}-\mathrm{q}_{\mathrm{t}}\right)$ versus $\mathrm{t}$ are used to determine the first-order rate constant, $\mathrm{k}_{1}$. It was found that the correlation coefficient $\left(\mathrm{R}^{2}\right)$ had low value $(<97 \%)$. The inapplicability of the pseudo-first-order model to describe the kinetics of $\mathrm{Pb}$ (II) by adsorption using PFSR adsorbents.

\section{Pseudo-second-order model}

The pseudo-second-order model is expressed as [16]:

$$
\frac{t}{q_{t}}=\frac{1}{k_{2} q_{e}^{2}}+\frac{t}{q_{e}}
$$

Where, $\mathrm{k}_{2}(\mathrm{~g} / \mathrm{mg} / \mathrm{min})$ is the second-order rate constant of adsorption. The plot of $t / q_{t}$ versus $t$ shows a linear relationship. Values of $\mathrm{k}_{2}$ and equilibrium adsorption capacity $\mathrm{q}_{\mathrm{e}}$ were calculated from the intercept and slope of the plot shown in Figure 8. The values of $\mathrm{R}^{2}$ were greater than 1 for $\mathrm{Pb}$ (II) ion concentrations.

\section{Intra-particle diffusion model}

The intraparticle diffusion model [17] was used to identify the diffusion mechanism during adsorption process. It is described using the following equation:

$$
\mathbf{q}_{\mathbf{t}}=\mathbf{k}_{\mathrm{id}} \mathbf{t}^{0.5}+\mathbf{C}
$$

Where, $\mathrm{k}_{\mathrm{id}}\left(\mathrm{mg} / \mathrm{g} / \mathrm{min}^{1 / 2}\right)$ is the rate constant of the intra-particle diffusion model and C (mg/g) reflects the boundary layer effect. The 
$\mathrm{k}_{\mathrm{id}}$ and $\mathrm{C}$ can be determined from the slope and intercept of the linear plot of $\mathrm{q}_{\mathrm{t}}$ against $\mathrm{t}^{0.5}$.

The pseudo-first-order, pseudo-second-order and intra-particle diffusion models were used to understand the kinetic nature of $\mathrm{Pb}$ (II) onto PFSR adsorption system. All the values were presented in Table 5. All the experimental data showed better agreement with pseudosecond-order model in terms of higher correlation coefficient value $\left(\mathrm{R}^{2}>1\right)$, which suggested the adsorption rate of $\mathrm{Pb}(\mathrm{II})$ onto PFSR might be controlled by chemisorptions mechanism. The rate controlling step consisted valence forces through sharing or exchange of electrons between the adsorbent surface and adsorbate ions and no involvement of mass transfer in solution.

\section{Effect of temperature and thermodynamic data}

The adsorption tests were performed by batch technique in single system at $308 \mathrm{~K}, 318 \mathrm{~K}$, and $328 \mathrm{~K}$, respectively. For kinetic studies, a series of $250 \mathrm{ml}$ flask were used and each flask was filled with PFSR at mass loadings $0.200 \mathrm{~g}$ for both $\mathrm{Pb}$ (II) solutions at $10 \mathrm{ppm}$ metal solutions. The percentage removals of $\mathrm{Pb}(\mathrm{II})$ are presented in Table 6 .

The frequently used thermodynamic parameters assessed in this study are; change in Gibbs free energy $\left(\Delta G^{\circ}\right)$, isosteric heat of

\begin{tabular}{|l|c|c|}
\hline Mathematical models & parameters & $\mathbf{P b}(\mathrm{II})$ \\
\hline First-order kinetics & $\mathrm{R}^{2}$ & 0.598 \\
& $\mathrm{k}_{1}(\mathrm{per} \mathrm{min})$ & 0.015 \\
\hline Second-order kinetics & $\mathrm{q}_{\mathrm{e}}(\mathrm{mg} / \mathrm{g})$ & 58.6 \\
\hline & $\mathrm{R}^{2}$ & 1 \\
& $\mathrm{k}_{2} \mathrm{~g} / \mathrm{mg} / \mathrm{min}$ & 4.250 \\
\hline Intra-particle diffusion & $\mathrm{q}_{\mathrm{e}}(\mathrm{mg} / \mathrm{g})$ & 58.82 \\
\hline & $\mathrm{R}^{2}$ & 0.814 \\
& $\mathrm{k}_{\mathrm{id}} \mathrm{g} / \mathrm{mg} / \mathrm{min}^{1 / 2}$ & 0.039 \\
\hline
\end{tabular}

Table 5: Kinetic parameters for the adsorption of $\mathrm{Pb}(\mathrm{II})$ on PFSR

Table 6: Effect of temperature.

\begin{tabular}{|l|c|c|c|c|c|c|}
\hline \multirow{2}{*}{ Metal ions } & \multicolumn{3}{|c|}{ Adsorption Efficiency (\%) } & \multicolumn{3}{c|}{ Amount of adsorbed, q (mg/g) } \\
\cline { 2 - 7 } & $308 \mathrm{~K}$ & $318 \mathrm{~K}$ & $328 \mathrm{~K}$ & $308 \mathrm{~K}$ & $318 \mathrm{~K}$ & $328 \mathrm{~K}$ \\
\hline $\mathrm{Pb}$ (II) & 98.0 & 98.2 & 98.5 & 63.2 & 63.3 & 63.5 \\
\hline
\end{tabular}

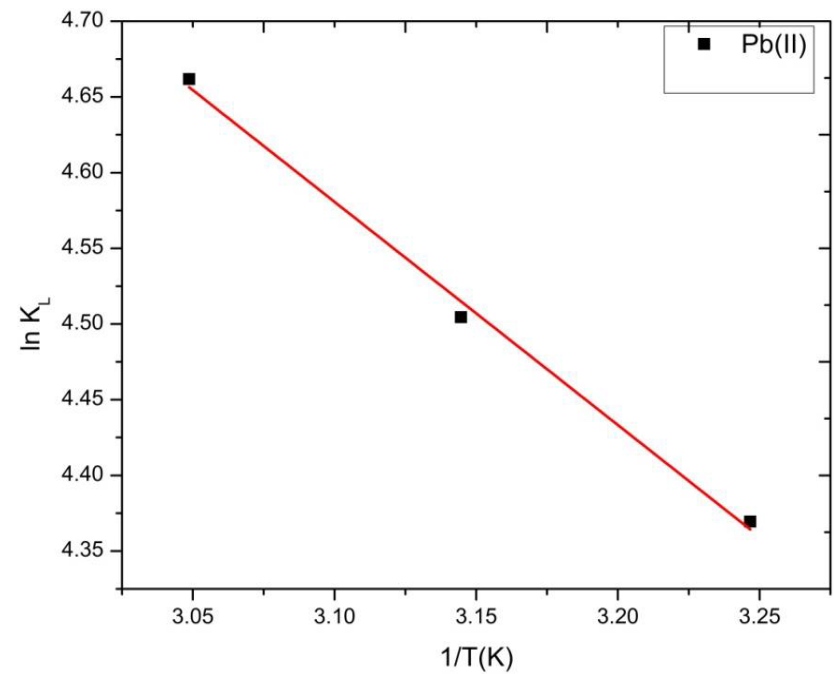

Figure 9: Van't Hoff plots of In $\mathrm{K}_{L}$ versus $1 / \mathrm{T}$ for the adsorption of $\mathrm{Pb}$ (II) onto PFSR.

\begin{tabular}{|l|c|c|c|c|c|c|}
\hline \multirow{2}{*}{ Metal ion } & \multicolumn{5}{|c|}{ Thermodynamics parameters } \\
\cline { 2 - 7 } & $\mathbf{R}^{\mathbf{2}}$ & $\begin{array}{c}\mathbf{\Delta} \mathbf{H}^{\mathbf{0}} \\
\mathbf{J} / \mathbf{m o l}\end{array}$ & $\begin{array}{c}\mathbf{\Delta} \mathbf{S}^{\mathbf{0}} \\
\mathbf{J} / \mathbf{m o l} \mathbf{K}\end{array}$ & \multicolumn{3}{|c|}{$\left.-\mathbf{\Delta G}^{\mathbf{0}} \mathbf{( k J / m o l}\right)$} \\
\hline $\mathrm{Pb}$ (II) & 0.996 & 12.26 & 76.09 & 111.8 & 119.0 & 127.1 \\
\hline
\end{tabular}

Table 7: Thermodynamic parameters for the adsorption of $\mathrm{Pb}(\mathrm{II})$ on PFSR.

adsorption $\left(\Delta \mathrm{H}^{\circ}\right)$ and the change in entropy $\left(\Delta \mathrm{S}^{\circ}\right)$ using VantHoff plot (Figure 9). The parameters are assessed using the equations.

$$
\begin{aligned}
& K_{L}=\frac{q_{e}}{c_{e}} \\
& \Delta G^{\circ}=-R T \ln K_{L} \\
& \ln K_{L}=\frac{\Delta S^{\circ}}{R}-\frac{\Delta H^{\circ}}{R T}
\end{aligned}
$$

Where, $\mathrm{K}_{\mathrm{L}}$ is the Langmuir constants; $\mathrm{C}_{e}$ is the concentration of solute adsorbed on the resin at equilibrium, $\mathrm{mg} / \mathrm{l}$. where $\mathrm{R}(8.314 \mathrm{~J} / \mathrm{mol}$ $\mathrm{K})$ is the gas constant, $\mathrm{T}(\mathrm{K})$ is the absolute temperature.

The correlation coefficient for the linear plot for $\mathrm{Pb}(\mathrm{II})$ was $\mathrm{R}^{2}=0.996$. Values of the standard Gibbs free energy change for the adsorption process obtained from Eq. (15) were listed in Table 7.

It is well known that these parameters can evaluate the orientation and feasibility of the physicochemical adsorptive reaction. The negative adsorption standard free energy changes $\left(\Delta \mathrm{G}^{\circ}\right)$ at all temperatures indicated that the adsorption of $\mathrm{Pb}$ (II) on PFSR was a general spontaneous process. In addition, the positive enthalpy change $\left(\Delta \mathrm{H}^{\circ}\right)$ values indicated that the $\mathrm{Pb}(\mathrm{II})$ adsorption on PFSR was an endothermic process. The positive value of the $\left(\Delta S^{\circ}\right)$ implies that the increment of an orderliness between the adsorbate and the adsorbent molecules.

\section{Desorption study}

Whether an adsorbent is an appropriate material in removal of metal ions from aqueous solutions depends not only on its adsorptive capacity, but also on its regeneration ability. For repeated use of an adsorbent, adsorbed metal ions should be easily desorbed under suitable conditions. In this work, desorption of metal ions with various concentrations of eluent solution was carried out. The results showed that the elution ratio is different under various eluent concentrations. Maximum recovery of $\mathrm{Pb}(\mathrm{II})$ at $100 \%$, was achieved with 2 and $3 \mathrm{M}$ $\mathrm{HCl}$ eluent solutions. In order to show the reusability of the adsorbent, adsorption-desorption cycle of metal ion was repeated five times by using the same beads. The adsorption capacities for the PFSR resin did not noticeably change (only a maximum $5 \%$ change was observed) during the repeated adsorption desorption operations. This can be attributed to decomposition effect of $\mathrm{HCl}$ used as stripping agent on adsorbent. These results show that the PFSR resin has good regeneration ability

\section{Conclusion}

The present study reported the mechanism of adsorption of $\mathrm{Pb}(\mathrm{II})$ onto PFSR prepared via polymerization method. Adsorption of the metal ion was dependent on metal ion concentration, contact time, dose and temperature. The $\mathrm{D}-\mathrm{R}$ and Temkin isotherm model provided the best fit for the $\mathrm{Pb}$ (II) ion, revealing the maximum adsorption capacity of $13.74 \mathrm{mg} / \mathrm{g}$.

Adsorption of $\mathrm{Pb}(\mathrm{II})$ ions was shown to be dependent on the dose and the optimum dose for the better adsorption was found to be $0.200 \mathrm{~g}$ for $\mathrm{Pb}(\mathrm{II})$ metal ions. Kinetic studies demonstrated that the mechanism 
Citation: Kannan RS, Kavitha K, Muthukrishnan P, Krishnan NP, llayaraja M (2015) Convenient Synthesis of Micron-sized Macro Porous Polymers with Silica on their Surfaces and Excellent Adsorption Performance for Pb(II) Ion. J Environ Anal Toxicol 5: 291. doi:10.4172/2161-0525.1000291

for adsorption of metal ions followed the pseudo-second-order rate model.

The thermodynamic studies revealed that the adsorption is spontaneous and endothermic for $\mathrm{Pb}(\mathrm{II})$ ions onto PFSR. The positive entropy indicated increase in the degree of freedom for the adsorbed species and suggests that there is an increase in the concentration of adsorbate in solid-solution interface. In future this adsorbent used to remove color effluent treatments and pesticide degradation process.

\section{References}

1. Ozay O, Ekici S, Baran Y, Aktas N, Sahiner N (2009) Removal of toxic metal ions with magnetic hydrogels. Water Res 43: 4403-4411.

2. Gupta VK, Suhas (2009) Application of low-cost adsorbents for dye removal--a review. J Environ Manage 90: 2313-2342.

3. Gupta VK, Rastogi A, Saini VK, Jain N (2006) Biosorption of copper(II) from aqueous solutions by Spirogyra species. J Colloid Interface Sci 296: 59-63.

4. Heidari A, Younesi H, Mehraban Z, Heikkinen H (2013) Selective adsorption of $\mathrm{Pb}(\mathrm{II}), \mathrm{Cd}(\mathrm{II})$, and $\mathrm{Ni}(\mathrm{II})$ ions from aqueous solution using chitosan-MAA nanoparticles. Int J Biol Macromol 61: 251-263.

5. Xu M, Zhang Y, Zhang Z, Shen Y, Zhao M, et al. (2011) Study on the adsorption of $\mathrm{Ca}^{2+}, \mathrm{Cd}^{2+}$ and $\mathrm{Pb}^{2+}$ by magnetic $\mathrm{Fe}_{3} \mathrm{O}_{4}$ yeast treated with EDTA dianhydride. Chemical Engineering Journal 168: 737-745.

6. Wan Ngah WS, Teong LC, Hanafiah MAKM (2011) Adsorption of dyes and heavy metal ions by chitosan composites: A review. Carbohydrate Polymers 83: $1446-1456$.
7. Karami H (2013) Heavy metal removal from water by magnetite nanorods. Chemical Eng J 219: 209-216.

8. Tirtom VN, Dincer A, Becerik S, Aydemir T, Celik A (2012) Comparative adsorption of $\mathrm{Ni}(\mathrm{II})$ and $\mathrm{Cd}(\mathrm{II})$ ions on epichlorohydrine cross linked chitosanclay composite beads in aqueous solution. Chemical Engineering Journal 197 379-386.

9. Li X, Qi Y, Li Y, Zhang Y, He X, et al. (2013) Novel magnetic beads based on sodium alginate gel cross linked by zirconium(IV) and their effective removal for $\mathrm{Pb}^{2+}$ in aqueous solutions by using a batch and continuous systems. Bioresour Tech 142: 611-619.

10. Hall KR, Eagleton LC, Acrivos A, Vermilion T (1966) Pore- and Solid-Diffusion Kinetics in Fixed-Bed Adsorption under Constant-Pattern Conditions. Ind Eng Chem Fund 5: 212-223.

11. Dubinin MM, Radushkevich LV (1947) Equation of the characteristic curve or activated charcoal. Proc Acad Sci USSR 55: 331-333.

12. Foo KY, Hameed BH (2010) Insights into the modeling of adsorption isotherm systems. Chem Eng J 156: 2-10.

13. Temkin MJ, Pyzhev V (1940) Kinetics of ammonia synthesis on promoted iron catalysts. Acta Physiochim URSS 12: 217-222.

14. Jovanoic DS (1969) Physical Adsorption of gases. Colloid Polym Sci 235: 1203-1214.

15. Lagergren S (1898) About the theory of so-called adsorption of soluble substance. Kungliga Svenska Vetenskaps-Akademiens Handlingar 24: 1-39.

16. Ho YS, Mckay G (1999) Pseudo-second order model sorption processes. Process Biochem 34: 451-465.

17. Mckay G, Blair HS, Gardner J (1983) The adsorption of dyes in chitin. III Intraparticle diffusion processes. J Appl Polym Sci 28: 1767-1778. 